\title{
Chemical Variation among Castes, Female Life Stages and Populations of the Facultative Eusocial Sweat Bee Halictus rubicundus (Hymenoptera: Halictidae)
}

\author{
Iris Steitz ${ }^{1}$ (I) Robert J Paxton ${ }^{2,3} \cdot$ Stefan Schulz ${ }^{4} \cdot$ Manfred Ayasse ${ }^{1}$ \\ Received: 2 October 2020 / Revised: 5 March 2021 / Accepted: 17 March 2021 / Published online: 31 March 2021 \\ (C) The Author(s) 2021
}

\begin{abstract}
In eusocial insects, chemical communication is crucial for mediating many aspects of social activities, especially the regulation of reproduction. Though queen signals are known to decrease ovarian activation of workers in highly eusocial species, little is known about their evolution. In contrast, some primitively eusocial species are thought to control worker reproduction through physical aggression by the queen rather than via pheromones, suggesting the evolutionary establishment of chemical signals with more derived sociality. However, studies supporting this hypothesis are largely missing. Socially polymorphic halictid bees, such as Halictus rubicundus, with social and solitary populations in both Europe and North America, offer excellent opportunities to illuminate the evolution of caste-specific signals. Here we compared the chemical profiles of social and solitary populations from both continents and tested whether (i) population or social level affect chemical dissimilarity and whether (ii) caste-specific patterns reflect a conserved queen signal. Our results demonstrate unique odor profiles of European and North American populations, mainly due to different isomers of n-alkenes and macrocyclic lactones; chemical differences may be indicative of phylogeographic drift in odor profiles. We also found common compounds overproduced in queens compared to workers in both populations, indicating a potential conserved queen signal. However, North American populations have a lower caste-specific chemical dissimilarity than European populations which raises the question if both use different mechanisms of regulating reproductive division of labor. Therefore, our study gives new insights into the evolution of eusocial behavior and the role of chemical communication in the inhibition of reproduction.
\end{abstract}

Keywords Halictid bee $\cdot$ Facultative eusocial behavior $\cdot$ Chemical communication $\cdot$ Regulation of reproduction $\cdot$ Population dialect

\section{Introduction}

Chemical communication plays a crucial role in insects, especially in taxa that live in social groups. Chemical signals are known to regulate many aspects of their social activities, including the

Iris Steitz

iris.steitz@gmx.net

1 Institute of Evolutionary Ecology and Conservation Genomics, University of Ulm, Ulm, Germany

2 General Zoology, Institute for Biology, Martin Luther University Halle-Wittenberg, Halle (Saale), Germany

3 German Centre for Integrative Biodiversity Research (iDiv) Halle-Jena-Leipzig, Leipzig, Germany

4 Departement of Life Sciences, Institute of Organic Chemistry, TU Braunschweig, Braunschweig, Germany mediation of various types of inter- and intracolonial recognition (Richard and Hunt 2013; Wilson 1965). It is thought that the complexity of chemical communication and information transfer increases across species with the complexity of their social organization (Leonhardt et al. 2016; Steitz et al. 2018). Insects comprise a huge variety of social organizations and interactions ranging from solitary species, were contact among conspecifics is very rare and limited to interactions of mates, to advanced eusocial species with a marked reproductive division of labor, in which every individual performs its specific task to the benefit of the colony (Wilson 1971).

In eusocial insects, chemical communication is known to be involved not only in nestmate and kin recognition but also in regulating reproductive division of labor and task allocation of individuals in the society (Ayasse et al. 2001; Kocher and Grozinger 2011; Rottler-Hoermann et al. 2016; Steitz and Ayasse 2020; Steitz et al. 2018, 2019). The castes, namely the reproductive queens and the non-reproductive workers, 
often differ in their chemical signatures and signals produced by queens or dominant females are thought to regulate many aspects of social behavior and reproduction within the colony (Le Conte and Hefetz 2008; Soro et al. 2011; Sramkova et al. 2008; Steitz and Ayasse 2020; Steitz et al. 2018, 2019; Oi et al. 2015). These chemical queen signals are known to decrease the ovarian activity of workers and have been the focus of much attention in various eusocial insect species, especially those with highly developed eusocial behavior (Ayasse and Jarau 2014; Holman et al. 2013; Holman et al. 2016; Monnin 2006; Oi et al. 2015; Smith et al. 2012, 2016; Sramkova et al. 2008; Van Oystaeyen et al. 2014). Despite this, in primitively eusocial insect species with a lack of morphologically distinct castes, it is thought that queens may regulate the reproduction of workers through physical aggression rather than through chemical signals (Bourke 1999; Oi et al. 2019; Smith and Liebig 2017). Maintenance of reproductive division of labor through queen behavior and not chemical signature has, for example, already been shown for Polistes wasps (Oi et al. 2019) and bumble bee species (Amsalem et al. 2017; Padilla et al. 2016; Starkey et al. 2019). However, a more recent study on a primitively eusocial sweat bee, Lasioglossum malachurum, revealed that queen chemical signals are indeed sufficient to decrease worker ovarian activity without any physical contact between the castes, indicating a more complex evolutionary picture of reproductive division of labor (Steitz and Ayasse 2020). Overall, little is known about the evolution of reproductive division of labor and caste-specific signals, in large part due to past focus on species with highly developed eusocial behavior rather than species with a more flexible social behavior. Indeed, these species with a higher flexibility of eusocial behavior might better represent the transition from solitary living to eusocial behavior and are therefore highly useful to get insights on this transition.

Halictid bees or sweat bees are ideal organisms to study the evolution of caste-specific traits as (i) they evolved eusociality much more recently than the advanced eusocial taxa such as the ants, honey bees and vespid wasps (Brady et al. 2006; Gibbs et al. 2012; Kocher and Paxton 2014), (ii) there was more than one independent origin of eusociality in the taxon (Brady et al. 2006; Gibbs et al. 2012; Greenberg 1979), (iii) they possess several reversals from eusociality back to solitary nesting (Danforth 2002; Danforth et al. 2003; Wcislo and Danforth 1997) and (iv) they show considerable diversity in social behavior, ranging from solitary to primitively eusocial species, and including communal and socially polymorphic forms (Michener 1974; Yanega 1989). Especially the socially polymorphic species, in which one species can express either social or solitary behavior, are suitable model organisms to study the evolution of caste-specific odor traits (e.g. queen signals) as they enable comparison among social and solitary behavioral forms in a potentially common genetic background (Kocher and Paxton 2014; Shell and Rehan 2018).
One especially interesting species is Halictus rubicundus, an ancestrally eusocial halictine species with a Holarctic distribution which exhibits social polymorphism, with both solitary and social nests in both North America and Europe (Danforth 2002; Danforth et al. 1999; Eickwort et al. 1996; Soucy 2002; Soucy and Danforth 2002; Yanega 1989; Field et al. 2010). Social living comprising at least two broods per year, one worker brood and one brood containing the sexuals, occurs in regions with longer growing seasons, e.g. in lower elevations, as in New York (Yanega 1989) or the Netherlands (Hogendoorn and Leys 1997). In cooler regions, e.g. at higher altitude or latitude as in the Rocky Mountains, Colorado (Eickwort et al. 1996) or in Scotland (Potts and Willmer 1997; Field et al. 2010), H. rubicundus is solitary and produces only one brood, containing the sexuals, per year.

A phylogeographic study of $H$. rubicundus based on mitochondrial DNA revealed that, in North America, eusocial populations clustered into one lineage and solitary populations clustered into a second lineage, independent of their geographic locality (Soucy and Danforth 2002), providing evidence for a genetic basis to their social behavior. This is reinforced by size differences; in North American social populations, queens and workers exhibit marked size variation whereas in North American solitary populations, individuals are of intermediary size (Soucy 2002). In Europe, in contrast, Soucy and Danforth (2002) showed that social and solitary populations all clustered together in a third lineage distant to the two North American lineages, suggesting considerable genetic differentiation between all North American and all European populations. Moreover, in Great Britain, H. rubicundus was shown to exhibit social plasticity; females collected from social nests could switch to solitary living when they were relocated to regions where H. rubicundus is natively solitary and vice versa (Field et al. 2010; Field et al. 2012). Social plasticity is also represented by body size differences, as originally solitary females, transplanted to regions where females are social, produced offspring of the same size as native social females (Field et al. 2012), though caste differences in size in Europe were modest in comparison to North American eusocial populations. Though Soro et al. (2010) have shown subtle genetic differentiation between eusocial and solitary population of European $H$. rubicundus using nuclear (microsatellite) markers, the common garden experiments of Field et al. (2010) indicate that social phenotype is to some extent plastic in sweat bees in response to local environmental conditions (Field et al. 2010, 2012).

Although, sweat bees and especially $H$. rubicundus are ideal organisms to study traits linked to the evolution of social behavior, including their chemical communication, few studies have addressed their chemical profiles or the evolution of caste-specific or queen signals. The chemical profile of one obligate eusocial halictid species, L. malachurum, is well characterized; it consists of compounds mainly belonging to 
the substance classes of n-alkanes, n-alkenes, macrocyclic lactones, isopentenyl esters of unsaturated fatty acids, and ethyl esters (Ayasse et al. 1993; Ayasse et al. 1999; Soro et al. 2011; Steitz et al. 2018; Steitz and Ayasse 2020). Whereas isopentenyl esters of unsaturated fatty acids play a key role in the female sex pheromone (Ayasse et al. 1999), macrocyclic lactones have been shown to mediate aggressive interactions between nest-founding queens (gynes; Smith and Weller 1989). Moreover, n-alkanes and macrocyclic lactones have been found in larger quantities in breeding queens compared with workers in L. malachurum (Ayasse et al. 1993, 1999; Steitz et al. 2018; Steitz and Ayasse 2020), though macrocyclic lactones are sufficient to influence worker behavior, distracting workers from activating their ovaries and therefore functioning as a queen signal in this species (Steitz and Ayasse 2020). Indeed, macrocyclic lactones are the single compound class which is at higher titer in queens compared to workers in several eusocial halictid bee species, suggesting that it may function as a queen pheromone among several species in this taxon (Steitz et al. 2018, 2019). Additionally, queens and workers are chemically more distinct in obligate eusocial compared to socially polymorphic species like H. rubicundus, indicating a more complex caste-specific chemical profile with a more complex degree of social organization in halictid bees (Steitz et al. 2018). Populationspecific differences and direct comparison among social and solitary populations of $\mathrm{H}$. rubicundus may shed further light on the evolution of caste-specific signals and their mode of regulating worker reproduction in sweat bees.

The aim of our study was to investigate early stages of caste differentiation by examining the chemical profiles of different castes and female life stages among $H$. rubicundus females from social and solitary populations in Europe and North America. We hypothesized that the chemical profiles of European and North American populations would be distinct due to geographic isolation and odor drift. Overlying these continental differences, we hypothesized patterns of potential queen signals in the social populations common to Europe and North America due to the same or similar evolutionary pathways to the regulation of worker reproduction. We complemented these analyses by measuring body sizes of different female groups of social and solitary European and North American females as a metric of caste.

\section{Material and Methods}

Bee Collection Halictus rubicundus females at various life stages were collected from sites in Europe and North America: 1) solitary nest foundresses $(n=20)$ and solitary breeding females $(\mathrm{n}=20)$ in spring and summer 2011 in Belfast, Northern Ireland; 2$)$ nest foundresses $(n=21)$, social breeding queens $(n=22)$ and workers $(n=47)$ of social populations in spring and summer 2013 in Bonn and Hayingen, Germany; 3$)$ solitary breeding females $(n=14)$ in summer 2016 in Gothic, Colorado, USA; and 4) breeding queens $(n=11)$ and workers $(n=37)$ of a social population in summer 2016 in Logan, Utah, USA (Fig. 1). We collected all females at their nest sites by using an insect net or a vacuum suction device as described in Soro et al. (2009). The bees were placed in individual, small plastic vials (Eppendorf tubes: $1.5 \mathrm{ml}$ ) and killed by freezing at $-40{ }^{\circ} \mathrm{C}$ for further use in chemical analyses. As chemical compounds, especially cuticular hydrocarbons are known to exhibit a long-term stability (Guillem et al. 2016; Martin et al. 2009), we exclude that the collection of bees in different years may have any impact on our results.

Chemical Analyses Frozen females were individually rinsed for $15 \mathrm{~s}$ in $500 \mu \mathrm{l}$-pentane (Uvasol, 99.5\%, Merck, Germany) to extract cuticle surface compounds. All extracts were concentrated under a gentle stream of nitrogen to $25 \%$ of the original volume. For quantitative analysis, $10 \mu 1 \mathrm{n}$ octadecane (stock solution: $100 \mu \mathrm{g} / \mathrm{ml}$ in $\mathrm{n}$-hexane) were added to each extract as an internal standard.

Chemical analyses were performed on an Agilent 7820 A Series gas chromatograph (Agilent Technologies, Germany) equipped with a non-polar DB-5 MS capillary column $(30 \mathrm{~m} \times 0.25 \mathrm{~mm}$ inner diameter, $\mathrm{J} \& \mathrm{~W})$ and a flame ionization detector using hydrogen as a carrier gas (constant flow, $2.0 \mathrm{ml} /$ $\mathrm{min})$. One microliter of each sample was injected splitless into the gas chromatograph (injector temperature: $310^{\circ} \mathrm{C}$ ), operating at $50^{\circ} \mathrm{C}$ for $1 \mathrm{~min}$, after which the split valve was opened, and the temperature was increased continuously by $10^{\circ} \mathrm{C} / \mathrm{min}$ to a final temperature of $310^{\circ} \mathrm{C}$. The structural elucidation of individual compounds was based on gas chromatography/ mass spectrometry (HP 6890 series, Hewlett-Packard, Germany; method as described above for GC, carrier gas: helium) and on the comparisons of mass spectra using references from the NIST11 library and GC retention times with those of authentic reference samples by using AMDIS 2.71 (Automated Mass Spectral Deconvolution and Identification System). The absolute amounts of all substances were determined by using Agilent ChemStation Software (Agilent Technologies, Germany) and the internal standard as a reference. In order to estimate relative proportions for further downstream analyses, absolute amounts of individual compounds were divided by the sum of the absolute amounts of all compounds and multiplied by 100 .

To identify the double bond positions in n-alkenes and macrocyclic lactones, we separated pools of extracts into polar (macrocyclic lactones) and unpolar (n-alkenes) fractions using the SPE-method (solid-phase extraction) according to $\mathrm{Na}$ et al. (1998). The double bond positions were identified by derivatizing with dimethyl disulfide (DMDS) according to Carlson et al. (1989). 

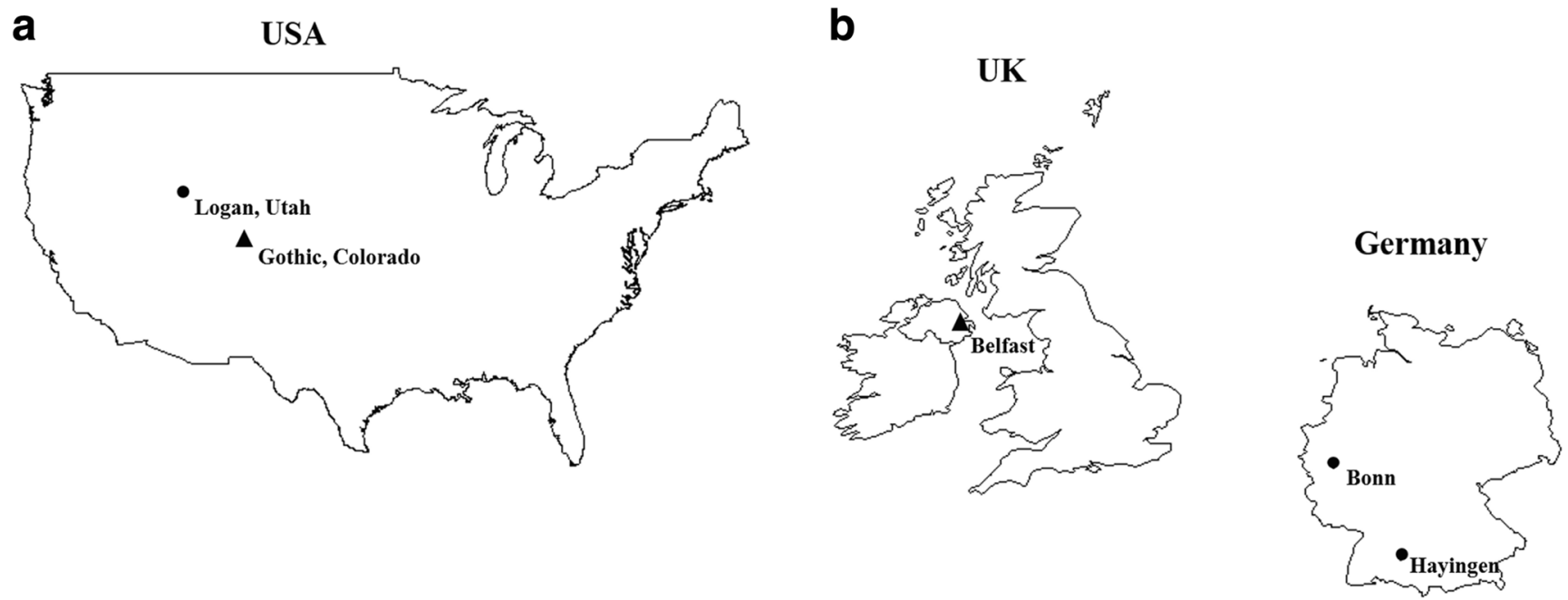

- social populations

$\Delta$ solitary populations

Fig. 1 Collection sites of H. rubicundus females from social (dot) and solitary (triangle) populations of (a) North America and (b) Europe

Measurement of Physiological State and Size After extraction of cuticle surfaces, all bees were dissected under a stereomicroscope to check ovarian stage, which was classified into five categories according to Duchateau and Velthuis (1989) so as to the physiological state and caste of each female. Head width (maximal width of the head including the compound eyes) was used as a proxy of size and was measured for each female using an eyepiece graticule.

Statistics Cuticular odor bouquets of $H$. rubicundus females from various life stages (social nest foundresses, social breeding queens, workers, solitary nest foundresses and solitary breeding females) were analyzed to test for differences among female groups, social organization (social vs. solitary) or population sites (Europe vs. North America). Relative amounts [\%] of each compound were calculated with respect to the total concentration of the whole bouquet; peaks with a concentration $<0.01 \%$ were excluded from downstream analyses.

To visualize dissimilarities between groups, we performed non-metric multidimensional scaling (NMDS) based on the Bray-Curtis dissimilarities, as implemented in Primer (Clarke and Gorley 2006). Furthermore, we performed oneway ANOSIM (analysis of similarities, permutations: 10,000) following post-hoc SIMPER tests to check for relative contributions of different compounds to detected differences between groups. To check for caste-specifically expressed compounds potentially involved in regulating the reproductive division of labor, we compared the expression level of each compound between breeding queens and workers from European and North American populations by performing univariate Mann-Whitney-U tests with Benjamini-Hochberg correction.

To compare chemical dissimilarities among female groups, social organization or population sites, we calculated Bray-
Curtis dissimilarities based on the square-root-transformed cuticle odor bouquet datasets (relative proportions) using the vegan package (Oksanen et al. 2017) of R v. 3.3.1 (R Core Team 2016). The obtained pairwise dissimilarity values were compared by using generalized linear models with a quasiPoisson error distribution followed by a Tukey post-hoc test for pairwise comparisons using the R packages stats and multcomp (Hothorn et al. 2008).

To check for size differences among females of different groups, population sites or social organization, we compared their head widths using linear models with log-transformed data followed by a Tukey post-hoc test for pairwise comparisons.

\section{Results}

Odor Profiles of Female Life Stages and Populations In total, we found 158 different chemical compounds among all tested H. rubicundus female groups. Overall, 52 of these compounds were exclusively found in females from North America, whereas 56 compounds were only found in the European females, including n-alkenes and macrocyclic lactones with different double bond positions (Fig. S1, Table S1). We found a clear separation of European females from North American females within each group (ANOSIM, global $R=0.801, P<$ 0.001 , all pairwise comparisons between European and North American females: $P<0.001$; Fig. $2 \mathrm{a}$, Table S2). The majority $(92,6 \%)$ of the identified compounds belong to six different compound classes: n-alkanes, n-alkenes, saturated and unsaturated macrocyclic lactones, fatty acids, ethyl esters and isopentenyl esters (Table S1).

Regarding only North America, social and solitary groups were chemically distinct (ANOSIM, global $R=0.512$, 
a

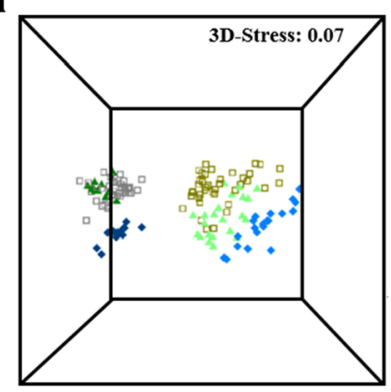

C

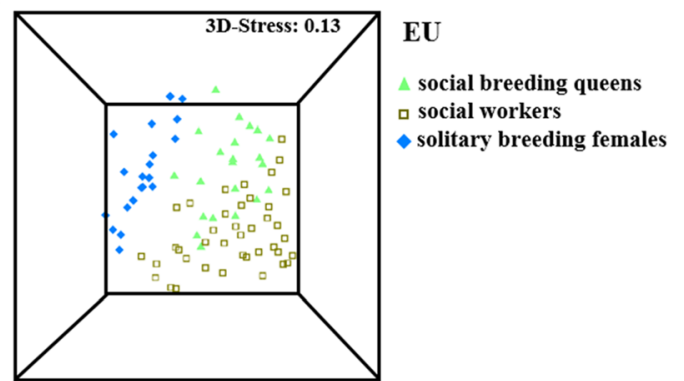

Fig. 2 Differences in cuticular chemical profiles among female groups based on relative amounts of compounds. In total, we compared (a) social (EU: $n=22$; USA: $n=11$ ) and solitary (EU: $n=20$; USA: $n=14$ ) breeding females and workers (EU: $n=47$; USA: $n=37$ ) between North American and European populations (NMDS, Bray-Curtis similarity measures, 3D-Stress: 0.07$)$, b social $(n=11)$ and solitary $(n=$ 14 ) breeding females and workers from North America (NMDS, BrayCurtis similarity measures, 3D-Stress: 0.12$)$, c social $(n=22)$ and solitary

$P<0.001$, all pairwise comparisons between solitary and social female groups: $P<0.001$; Fig. 2 b), whereas queens and workers were chemically not distinct (ANOSIM, global $R=$ $0.512, P<0.001$, pairwise comparison between queens and workers: $P=0.269$; Fig. $2 b$ ). Chemical dissimilarities between social and solitary females were mainly caused by different relative amounts of the n-alkanes heneicosane, tricosane, nonacosane and dotriacontane, the n-alkenes $(Z)$ 9-pentacosene, (Z)-11-heptacosene, $(Z)$-9-heptacosene and (Z)-7-nonacosene as well as three unknown compounds (SIMPER analyses, each compound contributed more than $2.0 \%$ to total Bray-Curtis dissimilarity; Fig. 3, Table S2).

Concerning only European populations, we also found distinct chemical profiles between social and solitary groups as well as between queens and workers within the social populations (ANOSIM, global $R=0.521, P<0.001$, all pairwise comparisons: $P<0.001$; Fig. $2 \mathrm{c}$ ). Chemical differences between social and solitary groups were mainly due to the relative amounts of the n-alkanes tricosane, pentacosane and heptacosane, the n-alkenes (Z)-11-pentacosene, $(Z)-11$ heptacosene, (Z)-11-nonacosene, (Z)-9-nonacosene, $(Z)-10$ hentriacontene and $(Z)$-12-tritriacontene as well as the saturated macrocyclic lactones 20-eicosanolide and 22-docosanolide and the unsaturated macrocyclic lactones $(Z)$-docos-11-en-22olide and (Z)-tetracos-11-en-24-olide (SIMPER analyses, each

b

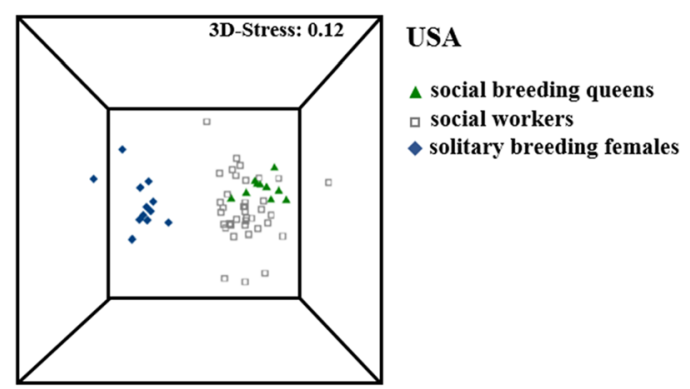

d

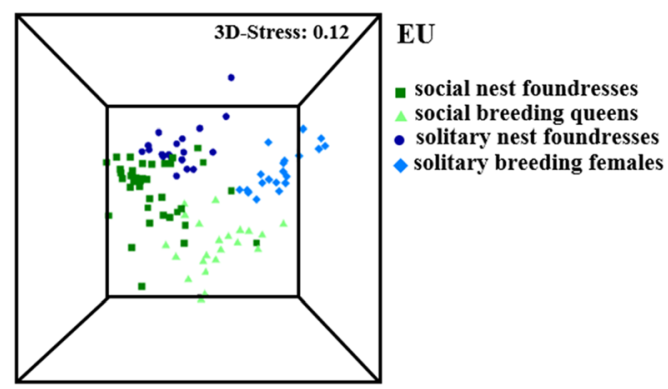

( $n=20)$ breeding females and workers $(n=47)$ from the European populations (NMDS, Bray-Curtis similarity measures, 3D-Stress: 0.13) and $\mathbf{d}$ social and solitary nest foundresses (social: $n=21$; solitary: $\mathrm{n}=$ 20 ) and breeding females (social: $n=22$; solitary: $n=20$ ) from the European populations (NMDS, Bray-Curtis similarity measures, 3DStress: 0.12). Stress-values represent the accuracy of the data representation in reduced dimensions. Stress-values $<0.2$ provide a good representation in the given number of dimensions

compound contributed more than $2.0 \%$ to total Bray-Curtis dissimilarity; Fig. 3, Table S2). European social breeding queens and workers were mainly chemically distinct due to the relative amounts of the $n$-alkanes tricosane, pentacosane and nonacosane, the n-alkenes $(Z)-11$-pentacosene, $(Z)-11$ heptacosene, $(Z)$-11-nonacosene, $(Z)$-9-nonacosene, $(Z)$-10hentriacontene and $(Z)-9$-hentriacontene as well as the saturated macrocyclic lactones 20-eicosanolide and 22-docosanolide (SIMPER analyses, each compound contributed more than $2.0 \%$ to total Bray-Curtis dissimilarity; Fig. 3, Table S2).

We also found clear chemical distinctions among nest founding females and breeding females, both among social and among solitary nesting bees from Europe (ANOSIM, global $R=0.544, P<0.001$, all pairwise comparisons: $P<0.001$; Fig. 2d). Differences between nest foundresses and breeding queens in social populations were mainly due to the relative amounts of the n-alkanes tricosane and nonacosane, the nalkenes (Z)-11-pentacosene, $(Z)$-11-heptacosene, $(Z)$-9heptacosene, (Z)-11-nonacosene, (Z)-9-nonacosene, $(Z)$-7nonacosene and $(Z)-10$-hentriacontene and the saturated macrocyclic lactones 20-eicosanolide and 22-docosanolide (SIMPER analyses, each compound contributed more than $2.0 \%$ to total Bray-Curtis dissimilarity; Fig. 3, Table S2). In comparison, nest foundresses and breeding females of solitary populations mainly differed due to the relative amounts of the 
Fig. 3 Heatmap of Bray-Curtis dissimilarities of those compounds which contributed most to the chemical differences of all tested female groups

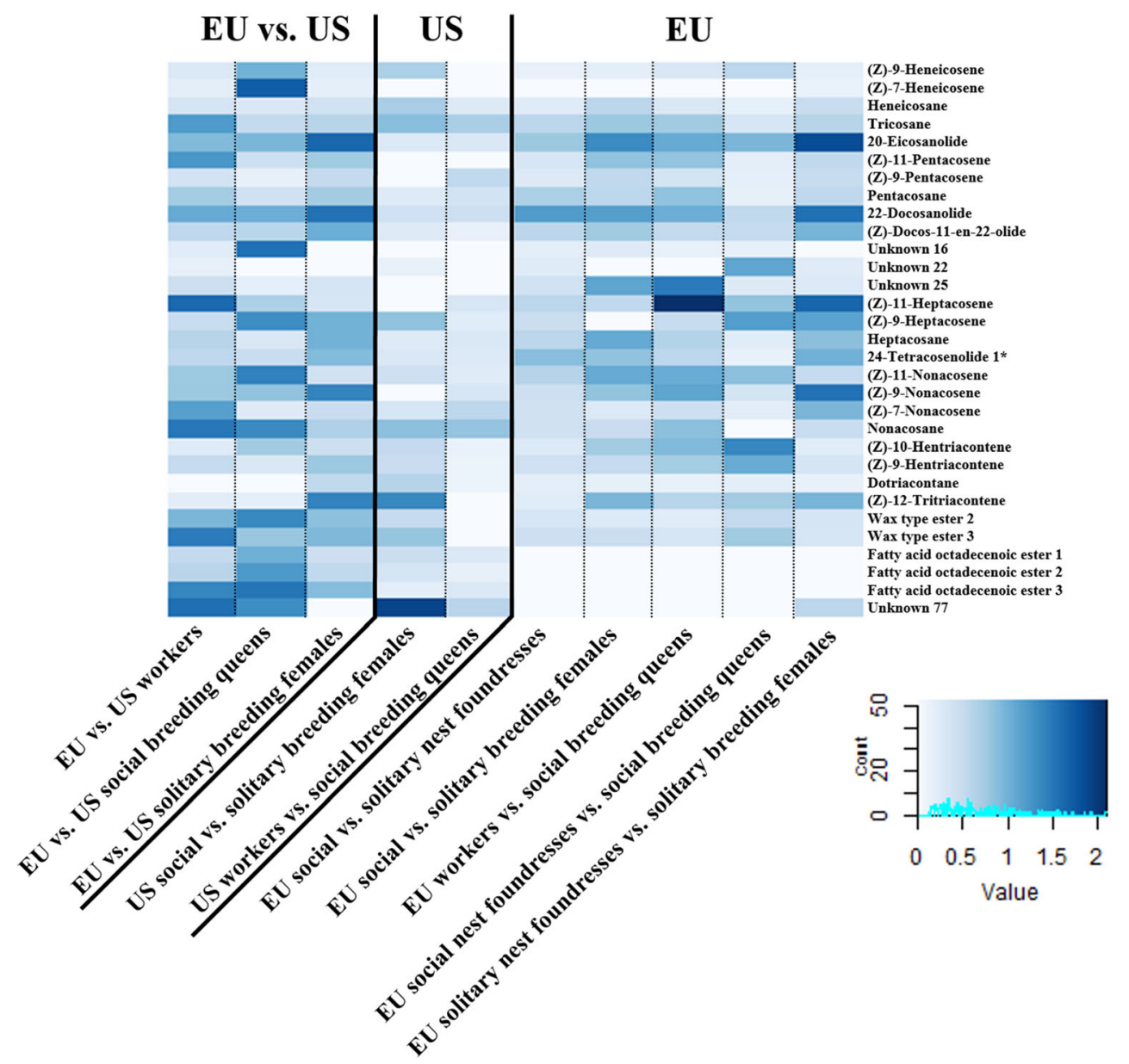

n-alkane heptacosane, the n-alkenes $(Z)$-11-heptacosene, $(Z)$ 9-heptacosene, $(Z)$-9-nonacosene, $(Z)$-7-nonacosene, $(Z)$-12tritriacontene, the saturated macrocyclic lactones 20eicosanolide and 22-docosanolide as well as the unsaturated macrocyclic lactones $(Z)$-docos-11-en-22-olide and $(Z)$ tetracos-11-en-24-olide (SIMPER analyses, each compound contributed more than $2.0 \%$ to total Bray-Curtis dissimilarity; Fig. 3, Table S2).

\section{Chemical Dissimilarities among Various Female Life Stages} and Populations We found higher chemical dissimilarities in chemical profiles between breeding queens and workers in the social nests from Europe compared to the social nests from North America (quasi-Poisson GLM, $F_{1,1018}=2425.3$, $P<0.001$; Fig. 4a). Despite this, we could not find any difference between comparisons among nestmates or nonnestmates in this queen-worker comparison (quasi-Poisson $\left.G L M, F_{1,1018}=34,732, P=0.775\right)$. In addition, we found higher chemical distinction between social and solitary breeding females in the European populations compared to those from North America (quasi-Poisson GLM, $F_{1,438}=351.77$, $P<0.001$; Fig. 4b). As we also collected nest founding females in Europe, we tested whether the dissimilarities in their chemical profiles was different for social and solitary populations. We found higher chemical distinction between nest foundresses and breeding females in social European populations compared to solitary populations (quasi-Poisson GLM, $F_{1,1006}=230.3, P<0.001$; Fig. $4 \mathrm{c}$ ). In addition, we checked whether nest founding females of social and solitary populations are chemically less distinct than breeding females of both populations or whether we could find similar patterns in both groups when females initiate breeding. We found higher chemical distinction in breeding females of social and solitary populations compared to nest foundresses (quasi-Poisson $G L M, F_{1,1078}=449.17, P<0.001$; Fig. $\left.4 d\right)$. Despite this, the inter-caste chemical dissimilarity of queens and workers from European populations was significantly higher than the intracaste dissimilarity (quasi-Poisson GLM, $F_{1,2002}=1392.1$, $P<0.001$; Fig. 5). This result was not true for North American populations, in which intra- and inter-caste chemical dissimilarity was not significantly different (quasi-Poisson $G L M, F_{1,2002}=1392.1, P=0.997$; Fig. 5).

Caste Differences of Single Chemical Compounds In univariate tests, we found caste-specific differences in the single amounts of chemical compounds between breeding queens 

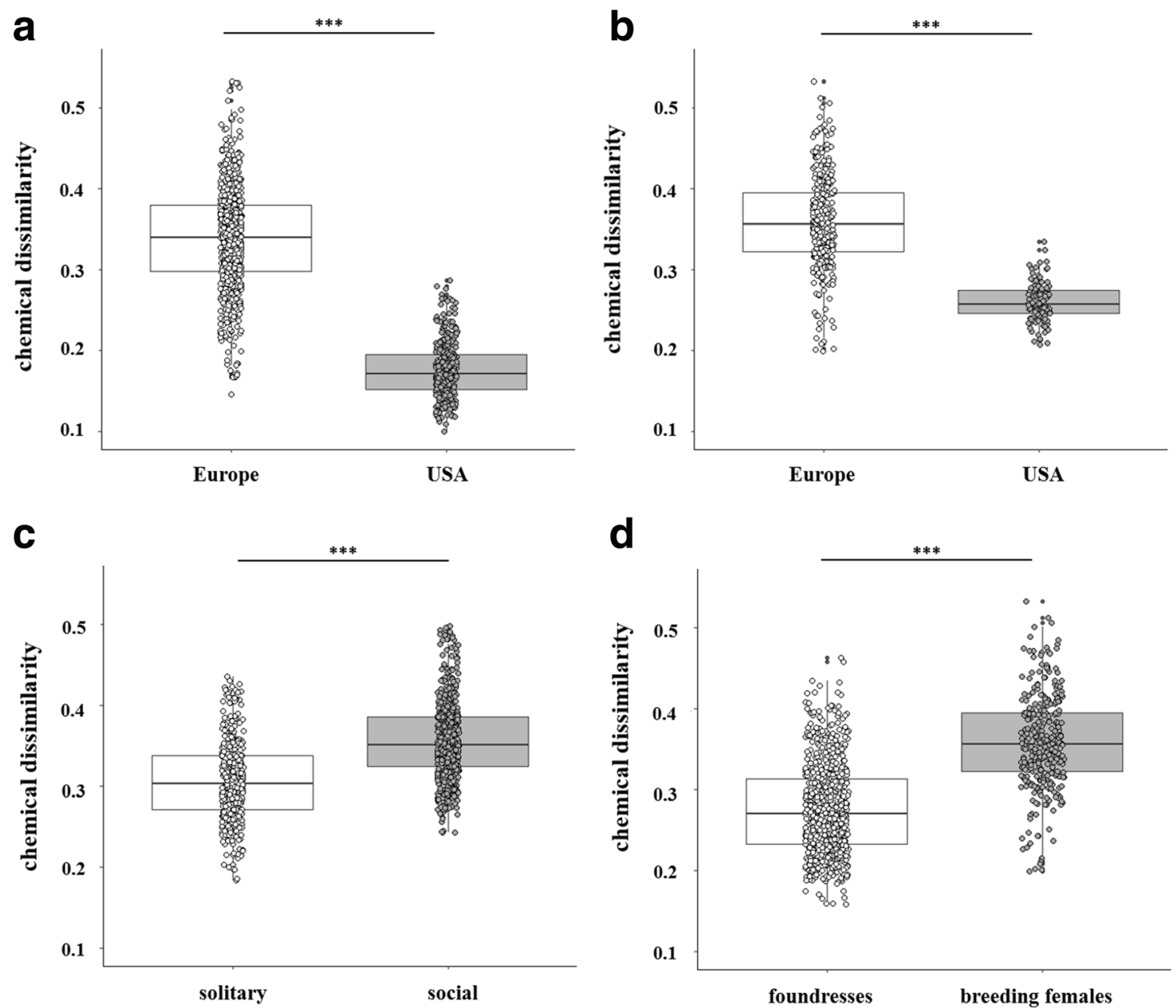

Fig. 4 Comparison of chemical distances (Bray-Curtis dissimilarities) between (a) queens (EU: $n=22$; USA: $n=11$ ) and workers (EU: $n=$ 47; USA: $n=37$ ) of social populations in Europe and North America, b social (EU: $n=22$; USA: $n=11$ ) and solitary (EU: $n=20$; USA: $n=14$ ) breeding females of populations in Europe and North America, $\mathbf{c}$ nest foundresses (solitary: $\mathrm{n}=20$; social: $n=21$ ) and breeding queens (solitary: $\mathrm{n}=20$; social: $\mathrm{n}=22$ ) in European solitary and social populations and $\mathbf{d}$ social (foundresses: $\mathrm{n}=21$; breeding females: $\mathrm{n}=22$ ) and solitary populations (foundresses and breeding females: $n=20$ ), comparing foundresses or breeding females of European populations.

and workers in both European (13 compounds) and North American (13 compounds) populations (Mann-Whitney- $U$ tests with Benjamini-Hochberg correction, adjusted $P<$ 0.05 ; Table 1) mainly belonging to the compound classes of n-alkanes, n-alkenes, methyl-alkanes and isopentenyl esters. However, there were only 3 compounds which showed a caste difference in both tested populations, whereas the majority of the compounds showed a caste-specific expression in either Europe or North America. Those compounds, which exhibited higher amounts in queens compared to workers in both populations were the n-alkane nonacosane and the isopentenyl ester 3-methyl 3-butenyl-(Z)-15- tetracosanoate, whereas an unknown compound was commonly overproduced in workers compared to queens (Table 1).

European populations exhibited higher chemical dissimilarities between castes (a; quasi-Poisson GLM, P<0.001) and social and solitary breeding females (b; quasi-Poisson GLM, P<0.001). Beside this, chemical distinction was higher between nest foundress and breeding queens in social than in solitary European populations (c; quasi-Poisson GLM, $P<0.001)$, whereas chemical dissimilarities were higher in breeding queens between social and solitary populations than in nest foundresses (d; quasi-Poisson GLM, $P<0.001$ ). Boxes represent the median and 25 th and 75 th percentile, and the overlaying dots represent all calculated data values

Body Size Differences In the European female groups, we found size differences between social breeding queens and solitary breeding females (linear model, $F_{5,146}=18.75$, $P<0.001$, following Tukey post-hoc tests, $P<0.001$; Fig. 6), but not between solitary breeding females and workers (linear model, $F_{5,146}=18.75, P<0.001$, following Tukey post-hoc tests, $P=0.99$; Fig. 6). Additionally, the European social breeding queens were larger than their workers (linear model, $F_{5,146}=18.75, P<0.001$, following Tukey post-hoc tests, $P<0.001$; Fig. 6). Despite this, size differences between breeding queens and workers was not different among nestmates or non-nestmates (linear model, $F_{3,405}=7.939$, $P=0.19$ ). Regarding North American populations, social breeding queens were larger than their workers (linear model, 
$\mathbf{E U}$

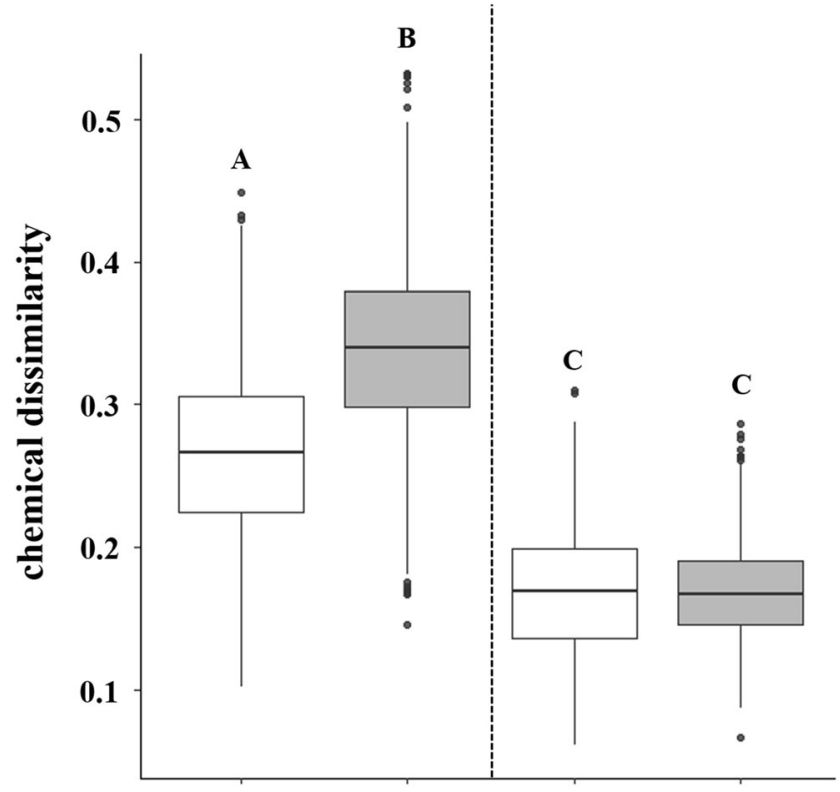

intra-caste inter-caste intra-caste inter-caste

Fig. 5 Comparison of chemical dissimilarities within castes (intra-caste, white) and between castes (inter-caste, grey) of social populations from Europe (EU) and North America (USA). In European populations, intracaste chemical dissimilarity was significantly lower than inter-caste chemical dissimilarity (quasi-Poisson GLM, P<0.001). Regarding North American females, intra-caste and inter-caste chemical dissimilarities did not differ significantly (quasi-Poisson GLM, $P=$ 0.997). Boxes represent the median and 25 th and 75 th percentile. Different letters indicate significant differences. Different letters indicate significant differences between the groups

$F_{5,146}=18.75, P<0.001$, following Tukey post-hoc tests, $P<0.001$; Fig. 6) independent of their nest affiliation (linear model, $F_{3,405}=7.939, P=0.99$ ) and solitary breeding females (linear model, $\mathrm{F}_{5,146}=18.75, P<0.001$, following Tukey post-hoc tests, $P<0.001$; Fig. 6 ), whereas solitary breeding females exhibited the same size as workers (linear model, $F_{5,146}=18.75, P<0.001$, following Tukey post-hoc tests, $P=0.99$; Fig. 6). Comparing females between the European and the North American populations, social breeding queens and solitary breeding queens from both sides of the Atlantic showed the same head widths (linear model, $F_{5,146}=18.75$, $P<0.001$, following Tukey post-hoc tests, social breeding: $P=0.91$, solitary breeding: $P=0.13$; Fig. 6), whereas workers (linear model, $F_{5,146}=18.75, P<0.001$, following Tukey post-hoc tests, $P<0.001$; Fig. 6$)$ were significantly larger in the European populations compared to the North American populations.

\section{Discussion}

In our study, we demonstrate that $H$. rubicundus females from European and North American populations are clearly chemically distinct, independent of their caste or physiological life stage. Additionally, social and solitary populations from both locations exhibit chemical dissimilarities, wherein the European females showed a higher caste-specific and lifestage-specific chemical dissimilarity than the North American ones. Indeed, queens and workers of North American populations could not even be distinguished based on their whole cuticular chemical profile, but only due to the amounts of some single compounds. This may indicate a different importance of inter-caste chemical communication systems between North American and European H. rubicundus populations. In Europe, we also found a higher chemical dissimilarity between nest foundresses and breeding females in the social populations compared to the solitary ones. Regarding body sizes, queens of European as well as North American populations were bigger than their workers, whereas the solitary breeding females of both continents were smaller than the social breeding queens and as small as the workers. Overall, the North American females tend to be smaller than the European females.

There was a clear distinction between European and North American populations. We identified more than $50 \mathrm{com}-$ pounds which were solely found either in the European and North American populations, including different isomers of $n$ alkenes and macrocyclic lactones, which indicates unique odor profiles that probably arose through chemical 'drift' analogous to differentiation through genetic drift for genetic markers. As cuticular hydrocarbons and also macrocyclic lactones are mainly synthesized by the insects themselves and do not have any environmental origin (Blomquist and Bagnères 2010; Holze et al. 2020; Schulz and Hötling 2015), we assume that the differences we found in cuticular chemical profiles are indeed based on genetic differences between populations. Comparable results have already been shown for different species of bumblebees (Bunk et al. 2010; Martin et al. 2010) or stingless bees (Martin et al. 2017), in which different nalkene isomers separate different species. This raises the question of whether the European and North American $H$. rubicundus females still belong to a single species. However, even if genetic studies demonstrated clearly distinct genetic lineages among both locations, compared to other insect species, divergence could still lie within the range of a single insect species (Soucy and Danforth 2002; Vogler et al. 1993). Nevertheless, the clear chemical distinction of both populations we demonstrated may stimulate more debate on this topic.

Beside this, we hypothesized the existence of caste-specific traits in $H$. rubicundus that were common to European and North American social and solitary populations. Most studies dealing with caste-specific signals in eusocial insects focus on queen signals which regulate worker reproduction; they often indicated conserved signals within a single species or even among several eusocial species of different evolutionary 
Table 1 Compounds with a significant caste-specific difference in European or North American populations (MannWhitney-U tests with BenjaminiHochberg correction, adjusted $p$ $<0.05)$. Grey cells indicate a lack of a significant difference in one of the tested populations

\begin{tabular}{|c|c|c|c|c|}
\hline \multirow[t]{2}{*}{ Compound name } & \multicolumn{2}{|l|}{ EU } & \multicolumn{2}{|l|}{ USA } \\
\hline & $\begin{array}{l}\text { adjusted } p \\
\text { value }\end{array}$ & $\begin{array}{l}\text { higher } \\
\text { expressed in }\end{array}$ & adjusted $\mathrm{p}$ value & $\begin{array}{l}\text { higher } \\
\text { expressed in }\end{array}$ \\
\hline (Z)-9-Pentacosene & $<0.001$ & worker & & \\
\hline Pentacosane & 0.036 & worker & & \\
\hline 3-Methylpentacosane & & & 0.049 & worker \\
\hline 3-Methyl 3-butenyl-(Z)-11-eicosenoate & 0.038 & worker & & \\
\hline Unknown 25 & $<0.001$ & queen & & \\
\hline (Z)-11-Heptacosene & $<0.001$ & worker & & \\
\hline (Z)-9-Heptacosene & & & 0.023 & worker \\
\hline Unknown 26 & 0.035 & worker & 0.032 & worker \\
\hline Heptacosane & 0.013 & queen & & \\
\hline Unknown 28 & & & 0.035 & worker \\
\hline Octacosane & & & 0.020 & queen \\
\hline (Z)-11-Nonacosene & 0.002 & queen & & \\
\hline (Z)-7-Nonacosene & & & 0.004 & queen \\
\hline Nonacosane & $<0.001$ & queen & 0.011 & queen \\
\hline 3-Methyl 3-butenyl-(Z)-15- tetracosanoate & $<0.001$ & queen & 0.002 & queen \\
\hline Unknown 50 & & & 0.048 & queen \\
\hline (Z)-10-Hentriacontene & 0.002 & queen & 0.049 & queen \\
\hline (Z)-9-Hentriacontene & 0.032 & queen & & \\
\hline Unknown 52 & & & 0.009 & queen \\
\hline (Z)-12-Tritriacontene & 0.040 & queen & & \\
\hline Unknown 73 & & & 0.004 & queen \\
\hline Unknown 76 & & & 0.012 & queen \\
\hline
\end{tabular}

lineages (Oi et al. 2015, 2016; Princen et al. 2020; Van Oystaeyen et al. 2014). This suggests that population 'dialects' may not represent caste-specific chemical signals such as queen signals, but may rather influence signals mediating kin or nestmate recognition in social insects. Indeed, there were two common single chemical compounds, the n-alkane nonacosane and the isopentenyl ester 3-methyl 3-butenyl-(Z)15-tetracosanoate, which are overproduced in queens compared to workers in both populations. If one or both of these compounds may have a function as a queen signal in both populations, it might be an indicator for a conservation of this signal in this species. However, without any behavior assays to test the effect of these compounds on the behavior or physiology of workers, this remains speculative and needs to be further investigated.

Regarding the complete cuticular chemical profile, queens and workers of North American populations seem to be chemically more similar than in Europe and even lack any clear distinction. This raises the question if and how North American and European social colonies differ in their regulation of the reproductive division of labor with European populations relying more on chemical regulation than North American ones. Indeed, it has been hypothesized that chemical regulation of worker reproduction evolved in larger colonies of social insects where behavioral regulation, such as aggressive interactions between the dominant and subordinate females, is limited by a high number of nestmates (Kocher and Grozinger 2011; Ratnieks et al. 2006). Studies on Polistes wasps (Toth et al. 2014; Oi et al. 2019) and queenless ants (Cuvillier-Hot et al. 2004; Monnin and Peeters 1999) provide evidence for such an evolutionary transition. It was shown, that dominant and subordinate females of these taxa indeed exhibit differences in their chemical profiles, but these chemical compounds were not sufficient to inhibit the ovarian activity in subordinate females. However, it is rather thought that chemical compounds in these species function as cues to support the effect of a dominant behavior in regulating the reproduction within the colony. These fertilitylinked compounds could easily evolve from these cues to real fertility signals or queen pheromones in higher eusocial species (Smith and Liebig 2017). Similar results were recently shown in queens of the bumblebees Bombus terrestris and B. impatiens, which need direct contact with their workers to inhibit their reproduction, thus queen-produced chemical signals may only function secondarily to augment behavioral cues (Amsalem et al. 2017; Kreuter et al. 2012; Padilla et al. 2016; Starkey et al. 2019). Regarding halictid bees, a recent study using different bioassays to examine the influence of 


\section{social breeding solitary breeding social workers queens females}

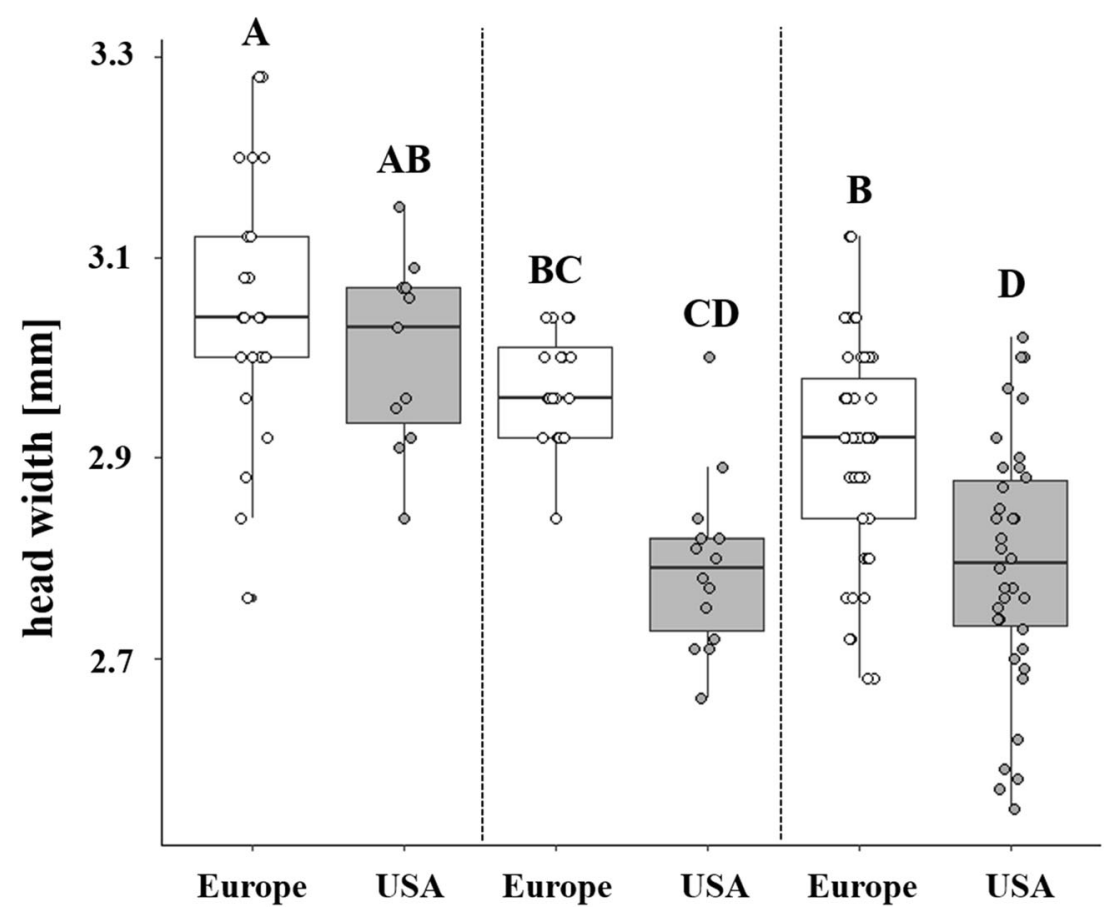

Fig. 6 Comparison of the head widths among social breeding queens (EU: $n=22$; USA: $n=11$ ), solitary breeding females (EU: $n=20$; USA: $n=14$ ) and workers (EU: $n=47$; USA: $n=37$ ) between European populations (white) and North American populations (grey). In populations from both continents, social breeding queens were larger than solitary breeding females (EU and USA: $L M$ and Tukey, $P<0.001$ ) and workers (EU and USA: $L M$ and Tukey, $P<0.001$ ), but solitary

queen-specific chemical compounds on worker behavior and reproductive physiology indicated that the chemical signal, namely macrocyclic lactones, is solely sufficient to function as a queen pheromone, decreasing worker ovarian activation in the obligate eusocial species L. malachurum (Steitz and Ayasse 2020). However, even if macrocyclic lactones were shown to be the single common compound class overproduced in queens compared to workers among several halictid bee species (Steitz et al. 2018), we cannot exclude the possibility of the use of behavioral cues to regulate worker reproduction among various halictid bee species. Indeed, as H. rubicundus is a facultative eusocial species with a less complex social behavior than e.g. L. malachurum or bumblebees, it is also likely that queens use behavioral cues to dominate worker reproduction rather than solely relying on chemical cues. Interestingly, the lower level of caste-specific chemical differences in North American populations suggests such a use of behavioral cues, whereas European females may also use chemical cues due to their clear caste-specific chemical profiles. Further studies, including behavioral assays similar to those described for L. malachurum (Steitz and Ayasse 2020) or bumblebees (Kreuter et al. 2012; Padilla et al. 2016), are needed to shed further light on this. breeding females exhibited the same size as workers (EU and USA: LM and Tukey, $P=0.99$ ). Beside this, workers from European populations were significantly larger than workers from North America ( $L M$ and Tukey, $P<0.001$ ). Boxes represent the median and 25 th and 75 th percentile, and the overlaying dots represent all calculated data values. Different letters indicate significant differences between the groups

Our results also clearly demonstrate that nest foundresses from social and solitary European populations are chemically more similar than social and solitary breeding females or queens. This leads us to the hypothesis that breeding females of social nests exhibit a queen-specific signal of sociality, as was recently shown in another eusocial halictine bee, L. pauxillum (Steitz et al. 2019). Even if it is hypothesized that queen signals evolved from chemicals associated with ovarian development (Oi et al. 2015; Smith and Liebig 2017; Steitz et al. 2018), the occurrence of this social signal in $H$. rubicundus cannot solely be explained by the development of ovaries, but also seems to be affected by social behavior as solitary breeding females change their odor composition to a different extent. Therefore, we would assume that social populations have a stronger or even more honest signal of their fertility than solitary females have. However, it is not appropriate to exclude environmental factors such as climatic conditions which might influence the genetic mechanisms of compound production, since the primary function of cuticular hydrocarbons in insects is to protect against dehydration and other environmental stresses as well as pathogen infection (Blomquist and Bagnères 2010). Indeed, insects are known to adjust their chemical cuticular profile to climatic conditions, 
not only due to different constant temperatures, but even daily fluctuations (Gibbs and Mousseau 1994; Hadley 1977; Sprenger et al. 2018). Especially for H. rubicundus, where the decision to nest either socially or solitarily probably depends on climatic conditions at the nesting site (Yanega 1989; Eickwort et al. 1996; Field et al. 2010), we cannot rule out the idea that the chemical differences we observed among the investigated populations may reflect different environmental or climatic condition at the nesting areas.

In addition to odor differences among populations, castes and breeding status, we also demonstrated that $H$. rubicundus females differ in their body size. Social breeding queens were overall bigger than their workers or solitary breeding queens, a result which we confirm in European and North American populations. North American females were overall smaller than their European counterparts. Soucy (2002) has already shown marked caste dimorphism in North American social $H$. rubicundus in which queens are larger than workers and solitary females. Indeed, bee size is known to be mainly influenced by temperature across several bee species (e.g. Kamm 1974; Radmacher and Strohm 2009; Richards and Packer 1996; Yanega 1989). It is usually assumed that there is an optimum temperature for a given body size such that both lower and higher temperatures cause more stress, resulting in a smaller body size of developing offspring (Soucy 2002). This may be explained by an increase in offspring number with an increasing temperature and consequently a decrease in body size due to a higher number of offspring. On the other side, a lower amount of pollen provisioning due to a lower number of available food sources at decreasing temperatures could also affect body size (Soucy 2002). The lower temperature at locations where $H$. rubicundus nests solitarily may therefore cause a smaller body size in solitary compared with social females. Beside this, the larger body size of European compared with North American populations may indicate that optimal environmental conditions cause a larger body size due to ideal temperature conditions compared to those in North America. Indeed, average temperature values in the summer months are much higher in Logan, Utah, USA than in Hayingen or Bonn, Germany, which may lead to a larger body size in European females than in North American ones. Body size may also influence social behavior, as bigger bees are known to behave more aggressively and to dominate in encounters with smaller bees (Smith and Weller 1989). Indeed, our results indicate that social breeding queens are bigger than their workers in Europe and North America; however, size differences between castes did not differ in North America versus Europe. Therefore, body size differences between castes suggest a similar degree of sociality in North America and Europe and may also be an indication for the use of cues other than chemical signals to maintain reproductive division of labor in $H$. rubicundus nests. Alternatively, the slightly larger worker size of European H. rubicundus vs. North American workers might hint at a greater reliance of European queens on chemical in addition to behavioral control of their workers in comparison to those of North America. However, these assumptions are only speculative and further analyses, including especially behavioral experiments on queen-worker behavior and regulation of reproductive division of labor are needed to shed more light on this.

In conclusion, our results clearly show that $H$. rubicundus females from North America and Europe exhibit distinct cuticular chemical profiles, which could be in the range of population dialects or may indicate ongoing speciation. North American and European queens have few common compounds overproduced in comparison to their workers, which might indicate a conservation of a queen signal in this species. However, bioassays testing the effect of these compounds on the behavior and physiology of workers are still needed to shed further light on this issue. As North American females show a lower chemical difference between queens and workers, we assume that the importance of behavioral cues vs. chemical signals in regulating worker reproduction may be different in North American and European populations. A more derived chemical dissimilarity between castes in Europe may indicate the involvement of chemical signals in the regulation of reproductive division of labor, whereas North American populations may also rely on other cues like aggressive behavior of the queen. However, we emphasize the importance of further studies, including behavioral tests, with facultative eusocial halictid bees to shed greater light on the different ways of regulating worker reproduction. This may give new insights into the evolution of social behavior and chemical communication in insects.

Supplementary Information The online version contains supplementary material available at https://doi.org/10.1007/s10886-021-01267-w.

Acknowledgements Open Access funding enabled and organized by Projekt DEAL. We thank the Rocky Mountain Biological Laboratory (RMBL) for equipment and access to study sites, especially Jennifer Reithel, Samantha Siegfried, Gesa Michel and Shannon Sprott. The authors also thank Jim Cane and Callum Kingwell for help and support in collecting bees and two anonymous reviewers for comments on a previous version of this manuscript. Iris Steitz was funded by the Studienstiftung des Deutschen Volkes via a doctoral scholarship.

Code Availability The codes generated during the current study are available from the corresponding author on request.

Authors' Contributions Conceptualization, I.S. and M.A.; Data curation, I.S.; Formal analysis, I.S.; Funding acquisition, I.S. and M.A.; Investigation, I.S., S.S.; Methodology, I.S., S.S. and M.A.; Project administration, M.A. and R.J.P.; Resources, M.A.; Supervision, R.J.P. and M.A.; Validation, I.S., S.S., R.J.P. and M.A.; Visualization, I.S. and M.A.;Writing — original draft, I.S.;Writing — review \& editing, S.S., R.J.P. and M.A.

Funding Iris Steitz was funded by the Studienstiftung des Deutschen Volkes via a doctoral scholarship. 
Data Availability The datasets generated during the current study are available from the corresponding author on request.

\section{Declarations}

Ethics Approval For this type of study formal consent is not required.

Consent to Participate Not applicable.

Consent for Publication Not applicable.

Conflicts of Interest/Competing Interests The authors declare no competing interests.

Open Access This article is licensed under a Creative Commons Attribution 4.0 International License, which permits use, sharing, adaptation, distribution and reproduction in any medium or format, as long as you give appropriate credit to the original author(s) and the source, provide a link to the Creative Commons licence, and indicate if changes were made. The images or other third party material in this article are included in the article's Creative Commons licence, unless indicated otherwise in a credit line to the material. If material is not included in the article's Creative Commons licence and your intended use is not permitted by statutory regulation or exceeds the permitted use, you will need to obtain permission directly from the copyright holder. To view a copy of this licence, visit http://creativecommons.org/licenses/by/4.0/.

\section{References}

Amsalem E, Padilla M, Schreiber PM, Altman NS, Hefetz A, Grozinger CM (2017) Do bumble bee, Bombus impatiens, queens signal their reproductive and mating status to their workers? J Chem Ecol 43 : 563-572. https://doi.org/10.1007/s10886-017-0858-4

Ayasse M, Jarau S (2014) Chemical ecology of bumble bees. Annu Rev Entomol 59:299-319. https://doi.org/10.1146/annurev-ento011613-161949

Ayasse M, Engels W, Hefetz A, Tengö J, Lübke G, Francke W (1993) Ontogenetic patterns of volatiles identified in Dufour's gland extracts from queens and workers of the primitively eusocial halictine bee, Lasioglossum malachurum (Hymenoptera: Halictidae). Insect Soc 40:41-58. https://doi.org/10.1007/BF01338831

Ayasse M, Engels W, Lübke G, Taghizadeh T, Francke W (1999) Mating expenditures reduced via female sex pheromone modulation in the primitively eusocial halictine bee, Lasioglossum (Evylaeus) malachurum (Hymenoptera: Halictidae). Behav Ecol Sociobiol 45: 95-106. https://doi.org/10.1007/s002650050543

Ayasse M, Paxton RJ, Tengö J (2001) Mating behavior and chemical communication in the order Hymenoptera. Annu Rev Entomol 46: 31-78. https://doi.org/10.1146/annurev.ento.46.1.31

Blomquist GJ, Bagnères AG (2010) Insect hydrocarbons: biology, biochemistry and chemical ecology. Cambridge University Press, Cambridge, USA

Bourke AFG (1999) Colony size, social complexity and reproductive conflict in social insects. J Evol Biol 12:245-257. https://doi.org/ 10.1046/j.1420-9101.1999.00028.x

Brady SG, Sipes S, Pearson A, Danforth BN (2006) Recent and simultaneous origins of eusociality in halictid bees. P Roy Soc Lond B Bio 273:1643-1649. https://doi.org/10.1098/rspb.2006.3496

Bunk E, Sramkova A, Ayasse M (2010) The role of trail pheromones in host nest recognition of the social parasitic bumblebees Bombus bohemicus and Bombus rupestris (Hymenoptera: Apidae).
Chemoecology 20:189-198. https://doi.org/10.1007/s00049-0100044-4

Carlson DA, Roan CS, Yost RA, Hector J (1989) Dimethyl disulfide derivatives of long chain alkenes, alkadienes, and alkatrienes for gas chromatography/mass spectrometry. Anal Chem 61:15641571. https://doi.org/10.1021/ac00189a019

Clarke KR, Gorley RN (2006) PRIMER V6: user manual-tutorial. Plymouth Marine Laboratory, Plymouth, UK

Cuvillier-Hot V, Lenoir A, Crewe R, Malosse C, Peeters C (2004) Fertility signalling and reproductive skew in queenless ants. Anim Behav 68:1209-1219. https://doi.org/10.1016/j.anbehav.2003.11. 026

Danforth BN (2002) Evolution of sociality in a primitively eusocial lineage of bees. PNAS 99:286-290. https://doi.org/10.1073/pnas. 012387999

Danforth BN, Sauquet H, Packer L (1999) Phylogeny of the bee genus Halictus (Hymenoptera: Halictidae) based on parsimony and likelihood analyses of nuclear EF- $1 \alpha$ sequence data. Mol Phylogenet Evol 13:605-618. https://doi.org/10.1006/mpev.1999.0670

Danforth BN, Conway L, Ji S (2003) Phylogeny of eusocial Lasioglossum reveals multiple losses of eusociality within a primitively eusocial clade of bees (Hymenoptera: Halictidae). Syst Biol 52:23-36. https://doi.org/10.1080/10635150390132687

Duchateau MJ, Velthuis HHW (1989) Ovarian development and egg laying in workers of Bombus terrestris. Entomol Exp Appl 51: 199-213. https://doi.org/10.1111/j.1570-7458.1989.tb01231.x

Eickwort GC, Eickwort JM, Gordon J, Eickwort MA, Wcislo WT (1996) Solitary behavior in a high-altitude population of the social sweat bee Halictus rubicundus (Hymenoptera: Halictidae). Behav Ecol Sociobiol 38:227-233. https://doi.org/10.1007/s002650050236

Field J, Paxton RJ, Soro A, Bridge C (2010) Cryptic plasticity underlies a major evolutionary transition. Curr Biol 20:2028-2031. https://doi. org/10.1016/j.cub.2010.10.020

Field J, Paxton R, Soro A, Craze P, Bridge C (2012) Body size, demography and foraging in a socially plastic sweat bee: a common garden experiment. Behav Ecol Sociobiol 66:743-756. https://doi.org/10. 1007/s00265-012-1322-7

Gibbs AG, Mousseau TA (1994) Thermal acclimation and genetic variation in cuticular lipids of the lesser migratory grasshopper (Melanoplus sanguinipes): effects of lipid composition on biophysical properties. Physiol Zool 67:1523-1543. https://doi.org/10.1086/ physzool.67.6.30163910

Gibbs J, Brady SG, Kanda K, Danforth BN (2012) Phylogeny of halictine bees supports a shared origin of eusociality for Halictus and Lasioglossum (Apoidea: Anthophila: Halictidae). Mol Phylogenet Evol 65:926-939. https://doi.org/10.1016/j.ympev.2012.08.013

Greenberg L (1979) Genetic component of bee odor in kin recognition. Science 206:1095-1097. https://doi.org/10.1126/science.206.4422. 1095

Guillem RM, Drijfhout FP, Martin SJ (2016) Species-specific cuticular hydrocarbon stability within European Myrmica ants. J Chem Ecol 42:1052-1062. https://doi.org/10.1007/s10886-016-0784-x

Hadley NF (1977) Epicuticular lipids of the desert Tenebrionid beetle, Eleodes armata: seasonal and acclimatory effects on composition. Insect Biochem 7:277-283. https://doi.org/10.1016/0020-1790(77) 90025-7

Hogendoorn K, Leys R (1997) Life-cycle of Halictus rubicundus Christ (Hymenoptera: Halictidae) in the Netherlands: comparison of two populations. J Kansas Entomol Soc 70:347-352

Holman L, Lanfear R, d'Ettorre P (2013) The evolution of queen pheromones in the ant genus Lasius. J Evolution Biol 26:1549-1558. https://doi.org/10.1111/jeb.12162

Holman L, Hanley B, Millar JG (2016) Highly specific responses to queen pheromone in three Lasius ant species. Behav Ecol Sociobiol 70:387-392. https://doi.org/10.1007/s00265-016-2058-6 
Holze H, Schrader L, Buellesbach J (2020) Advances in deciphering the genetic basis of insect cuticular hydrocarbon biosynthesis and variation. Heredity 126:1-16. https://doi.org/10.1038/s41437-02000380-y

Hothorn T, Bretz F, Westfall P (2008) Simultaneous inference in general parametric models. Biom J 50:346-363. https://doi.org/10.1002/ bimj.200810425

Kamm DR (1974) Effects of temperature, day length, and number of adults on the sizes of cells and offspring in a primitively social bee (Hymenoptera: Halictidae). J Kans Entomol Soc 47:8-18 https:// www.jstor.org/stable/25082614

Kocher SD, Grozinger CM (2011) Cooperation, conflict, and the evolution of queen pheromones. J Chem Ecol 37:1263-1275. https://doi. org/10.1007/s10886-011-0036-z

Kocher SD, Paxton RJ (2014) Comparative methods offer powerful insights into social evolution in bees. Apidologie 45:289-305. https:// doi.org/10.1007/s13592-014-0268-3

Kreuter K, Bunk E, Lückemeyer A, Robert T, Francke W, Ayasse M (2012) How the social parasitic bumblebee Bombus bohemicus sneaks into power of reproduction. Behav Ecol Sociobiol 66:475486. https://doi.org/10.1007/s00265-011-1294-z

Le Conte Y, Hefetz A (2008) Primer pheromones in social Hymenoptera. Annu Rev Entomol 53:523-542. https://doi.org/10.1146/annurev. ento.52.110405.091434

Leonhardt SD, Menzel F, Nehring V, Schmitt T (2016) Ecology and evolution of communication in social insects. Cell 16

Martin SJ, Zhong W, Drijfhout FP (2009) Long-term stability of hornet cuticular hydrocarbons facilitates chemotaxonomy using museum specimens. Biol J Linn Soc 96:732-737. https://doi.org/10.1016/j. cell.2016.01.035

Martin SJ, Carruthers JM, Williams PH, Drijfhout FP (2010) Host specific social parasites (Psithyrus) indicate chemical recognition system in bumblebees. J Chem Ecol 36:855-863. https://doi.org/10. 1007/s10886-010-9805-3

Martin SJ, Shemilt S, da S. Lima CB, de Carvalho CAL (2017) Are isomeric alkenes used in species recognition among neo-tropical stingless bees (Melipona spp). J Chem Ecol 43:1066-1072. https:// doi.org/10.1007/s10886-017-0901-5

Michener C (1974) The social behavior of the bees: a comparative study. Harvard University Press, Cambridge, Massachusetts, USA

Monnin T (2006) Chemical recognition of reproductive status in social insects. Annal Zool Fenn 43:515-530

Monnin T, Peeters C (1999) Dominance hierarchy and reproductive conflicts among subordinates in a monogynous queenless ant. Behav Ecol 10:323-332. https://doi.org/10.1093/beheco/10.3.323

$\mathrm{Naß} \mathrm{R,} \mathrm{Markstädter} \mathrm{C,} \mathrm{Hauke} \mathrm{V,} \mathrm{Riederer} \mathrm{M} \mathrm{(1998)} \mathrm{Quantitative} \mathrm{gas}$ chromatographic analysis of plant cuticular waxes containing long-chain aldehydes. Phytochem Analysis 9:112-118

Oi CA, van Zweden JS, Oliveira RC, Van Oystaeyen A, Nascimento FS, Wenseleers $T$ (2015) The origin and evolution of social insect queen pheromones: novel hypotheses and outstanding problems. BioEssays 37:808-821. https://doi.org/10.1002/bies.201400180

Oi CA, Millar JG, van Zweden JS, Wenseleers T (2016) Conservation of queen pheromones across two species of vespine wasps. J Chem Ecol 42:1175-1180. https://doi.org/10.1007/s10886-016-0777-9

Oi CA, Oliveira RC, van Zweden JS, Mateus S, Millar JG, Nascimento FS, Wenseleers T (2019) Do primitively eusocial wasps use queen pheromones to regulate reproduction? A case study of the paper wasp Polistes satan. Front Ecol Evol 7:199. https://doi.org/10. 3389/fevo.2019.00199

Oksanen J, Guillaume Blanchet F, Friendly M, Kindt R, Legendre P, McGlinn D, Minchin PR, O'Hara RB, Simpson GL, Solymos P, Henry M, Stevens H, Szoecs E, Wagner H (2017) Vegan: community ecology package. $\mathrm{R}$ package version $2: 4-3 \mathrm{https}$ :/CRAN.Rproject.org/package= $=$ vegan
Padilla M, Amsalem E, Altman N, Hefetz A, Grozinger CM (2016) Chemical communication is not sufficient to explain reproductive inhibition in the bumblebee Bombus impatiens. R Soc Open Sci 3: 160576. https://doi.org/10.1098/rsos.160576

Potts S, Willmer P (1997) Abiotic and biotic factors influencing nest-site selection by Halictus rubicundus, a ground-nesting halictine bee. Ecol Entomol 22:319-328. https://doi.org/10.1046/j.1365-2311. 1997.00071.x

Princen SA, Van Oystaeyen A, Peti C, van Zweden JS, Wenseleers T (2020) Cross-activity of honeybee queen mandibular pheromone in bumblebees provides evidence for sensory exploitation. Behav Ecol 31:303-310. https://doi.org/10.1093/beheco/arz191

R Core Team (2016) R: a language and environment for statistical computing R Foundation for statistical computing, Vienna. Austria, URL https://www.R-Rproject.org/

Radmacher S, Strohm E (2009) Factors affecting offspring body size in the solitary bee Osmia bicornis (Hymenoptera, Megachilidae). Apidologie 41:169-177. https://doi.org/10.1051/apido/2009064

Ratnieks FLW, Foster KR, Wenseleers T (2006) Conflict resolution in insect societies. Annu Rev Entomol 51:581-608. https://doi.org/10. 1146/annurev.ento.51.110104.151003

Richard FJ, Hunt JH (2013) Intracolony chemical communication in social insects. Insect Soc 60:275-291. https://doi.org/10.1007/s00040013-0306-6

Richards MH, Packer L (1996) The socioecology of body size variation in the primitively eusocial sweat bee, Halictus ligatus (Hymenoptera: Halictidae). Oikos 77:68-76. https://doi.org/10. 2307/3545586

Rottler-Hoermann A-M, Schulz S, Ayasse M (2016) Nest wax triggers worker reproduction in the bumblebee Bombus terrestris. R Soc Open Sci 3:150599. https://doi.org/10.1098/rsos.150599

Schulz S, Hötling S (2015) The use of the lactone motif in chemical communication. Nat Prod Rep 32:1042-1066. https://doi.org/10. 1039/c5np00006h

Shell WA, Rehan SM (2018) Behavioral and genetic mechanisms of social evolution: insights from incipiently and facultatively social bees. Apidologie 49:13-30. https://doi.org/10.1007/s13592-0170544-0

Smith AA, Liebig J (2017) The evolution of cuticular fertility signals in eusocial insects. Curr Opin Insect Sci 22:79-84. https://doi.org/10. 1016/j.cois.2017.05.017

Smith B, Weller C (1989) Social competition among gynes in halictine bees: the influence of bee size and pheromones on behavior. J Insect Behav 2:397-411. https://doi.org/10.1007/BF01068064

Smith AA, Millar JG, Hanks LM, Suarez AV (2012) Experimental evidence that workers recognize reproductives through cuticular hydrocarbons in the ant Odontomachus brunneus. Behav Ecol Sociobiol 66:1267-1276. https://doi.org/10.1007/s00265-012-1380-x

Smith AA, Millar JG, Suarez AV (2016) Comparative analysis of fertility signals and sex-specific cuticular chemical profiles of Odontomachus trap-jaw ants. J Exp Biol 219:419-430. https://doi. org/10.1242/jeb. 128850

Soro A, Ayasse M, Zobel MU, Paxton RJ (2009) Complex sociogenetic organization and the origin of unrelated workers in a eusocial sweat bee, Lasioglossum malachurum. Insect Soc 56:55-63. https://doi. org/10.1007/s00040-008-1037-y

Soro A, Bridge C, Field J, Cardinal SC, Paxton RJ (2010) Genetic differentiation across the social transition in a socially polymorphic sweat bee, Halictus rubicundus. Mol Ecol 19:3351-3363. https:// doi.org/10.1111/j.1365-294X.2010.04753.x

Soro A, Ayasse M, Zobel MU, Paxton RJ (2011) Kin discriminators in the eusocial sweat bee Lasioglossum malachurum: the reliability of cuticular and Dufour's gland odours. Behav Ecol Sociobiol 65:641653. https://doi.org/10.1007/s00265-010-1066-1 
Soucy SL (2002) Nesting biology and socially polymorphic behavior of the sweat bee Halictus rubicundus (Hymenoptera: Halictidae). Ann Entomol Soc Am 95:57-65

Soucy SL, Danforth BN (2002) Phylogeography of the socially polymorphic sweat bee Halictus rubicundus (Hymenoptera: Halictidae). Evolution 56:330-341

Sprenger PP, Burkert LH, Abou B, Federle W, Menzel F (2018) Coping with the climate: cuticular hydrocarbon acclimation of ants under constant and fluctuating conditions. J Exp Biol 221:jeb171488. https://doi.org/10.1242/jeb.171488

Sramkova A, Schulz C, Twele R, Francke W, Ayasse M (2008) Fertility signals in the bumblebee Bombus terrestris (Hymenoptera: Apidae). Naturwissenschaften 95:515-522. https://doi.org/10.1007/s00114008-0353-4

Starkey J, Brown A, Amsalem E (2019) The road to sociality: brood regulation of worker reproduction in the simple eusocial bee Bombus impatiens. Anim Behav 154:57-65. https://doi.org/10. 1016/j.anbehav.2019.06.004

Steitz I, Ayasse M (2020) Macrocyclic lactones act as a queen pheromone in a primitively eusocial sweat bee. Curr Biol 30:1136-1141.e3. https://doi.org/10.1016/j.cub.2020.01.026

Steitz I, Kingwell C, Paxton RJ, Ayasse M (2018) Evolution of castespecific chemical profiles in halictid bees. J Chem Ecol 44:827-837. https://doi.org/10.1007/s10886-018-0991-8

Steitz I, Brandt K, Biefel F, Minat Ä, Ayasse M (2019) Queen recognition signals in two primitively eusocial halictid bees: evolutionary conservation and caste-specific perception. Insects 10:416. https:// doi.org/10.3390/insects 10120416

Toth AL, Tooker JF, Radhakrishnan S, Minard R, Henshaw MT, Grozinger CM (2014) Shared genes related to aggression, rather than chemical communication, are associated with reproductive dominance in paper wasps (Polistes metricus). BMC Genomics 15:75. https://doi.org/10.1186/1471-2164-15-75

Van Oystaeyen A, Oliveira RC, Holman L, van Zweden JS, Romero C, Oi CA, d'Ettorre P, Khalesi M, Billen J, Wäckers F, Millar JG, Wenseleers T (2014) Conserved class of queen pheromones stops social insect workers from reproducing. Science 343:287-290. https://doi.org/10.1126/science. 1244899

Vogler AP, Desalle R, Assmann T, Knisley CB, Schultz TD (1993) Molecular population genetics of the endangered tiger beetle Cicindela dorsalis (Coleoptera: Cicindelidae). Ann Entomol Soc Am 86:142-152. https://doi.org/10.1093/aesa/86.2.142

Wcislo WT, Danforth BN (1997) Secondary solitary: the evolutionary loss of social behavior. Trends Ecol Evol 12:468-474. https://doi. org/10.1016/S0169-5347(97)01198-1

Wilson EO (1965) Chemical communication in the social insects. Science 149:1064-1071. https://doi.org/10.1126/science.149.3688.1064

Wilson EO (1971) The insect societies. Belknap Press of Harvard University Press, Cambridge

Yanega D (1989) Caste determination and differential diapause within the first brood of Halictus rubicundus in New York (Hymenoptera: Halictidae). Behav Ecol Sociobiol 24:97-107 